\title{
Losing Control of Company Information in the Recruitment Process: The Impact of LinkedIn on Organizational Attraction
}

\author{
R.L. Brouer, $\mathrm{PhD}$ \\ Canisius College \\ brouerr@canisius.edu \\ M.A. Stefanone, \\ $\mathrm{PhD}$ \\ University at Buffalo \\ Ms297@,buffalo.edu
}

\author{
R.L. Badawy, PhD \\ Youngstown State \\ University \\ rbadawy@ysu.edu
}

\author{
M.J. Egnoto \\ Ithaca College \\ megnoto@ithaca.edu
}

\author{
S.R. Seitz \\ California State \\ University \\ stephanie.seitz@,csueas \\ tbay.edu
}

\begin{abstract}
Social media provides access to diverse and potentially conflicting information about organizations to potential job candidates. However, little is known about the impact of conflicting information between social media and corporate websites for recruitment and attraction. Using an experimental design, we exposed participants to a fictitious company website promoting an employer brand of diversity. Participants were then randomly shown a fictitious LinkedIn employee search result page depicting high- or lowemployee diversity. Using the instrumental-symbolic framework and warranting theory, we posit that consistent information from LinkedIn will result in more positive image perceptions of organizations, ultimately leading to higher organizational attraction. Results show that participants who were exposed to information consistent with the organizational website promoting diversity rated that organization higher in agreeableness, and perceived agreeableness fully mediated the relationship between the experimental condition and organizational attractiveness.
\end{abstract}

\section{Introduction}

The recruitment of qualified employees is paramount for organizations today [36]. A key to recruiting the qualified candidates is for the organization to be seen as attractive as viewed by the applicant[36], and a positive image can lead to a competitive advantage in recruitment [25]. The extant literature largely focuses on different types of images and how these are related to attraction [24]. However, less is known about how perceptions of images are formed [14].

Additionally, little research exists on online recruitment in corporate websites, job boards, LinkedIn, etc., [21]. Yet, the use of these sites is on the rise, with Capelli [10] reporting that $90 \%$ of U.S. companies use their website for dispersing recruitment information. A survey by Jobvite found that $83 \%$ of recruiters are currently using or plan to use social media in recruitment, with $86 \%$ indicating that LinkedIn was their top choice [26].

The limited research done on company websites has focused on usability and design $[1,10,19,20]$, and research on social network sites (SNS) has either been descriptive or examined the usefulness of these sites for selection, not recruitment $[9,17,18]$. This represents a gap in the literature and a problem for practitioners as they rely on Internet recruitment more without research on its effectiveness.

Organizations use corporate websites as sources of strategic information about their image [10, 37, 40, 41], and in light of the ever-increasing diversity in the workplace [42], many organizations choose to portray their employer brand as embracing diversity [3]. A look at some Fortune 500 companies, such as Wegman's Coca-Cola, IBM, and Boeing indicates that they strategically espouse diversity on their websites.

That said, acknowledging that corporate image is the product of data-driven employer branding strategies that some might even see as a marketing gimmick, which are intended to promote images that are consistent with audience expectations, the strategic images organizations promote about themselves may not be consistent with reality. In the case of organizational diversity, defined for the purposes of this manuscript as surface-level, demographic diversity (e.g., race, gender, color) [41], it seems clear that organizations realize potential employees value diversity [3], and while organizations may promote the diversity of their employees, this employer brand may not reflect the actual diversity of their employees.

Today, potential applicants have access to varied sources of information about organizations beyond the corporate website, ranging from news coverage to content made available on social media platforms, such as LinkedIn. The growing popularity of SNS makes the prevalence of third party information about organizations readily accessible. The question then 
becomes what happens when an organization's website portrays a different image (i.e., we value diversity) than information gleaned from SNS (i.e., depict a homogenous all white workforce). Consistent with the warranting principle [45], we argue that information about organizations from sources other than the organization is an influential and important resource for potential applicants who are in the process of evaluating the attractiveness of organizations. Thus, we propose that there are real and negative consequences (i.e., lower ratings of corporate character and organizational attraction) for organizations that espouse diversity as part of their employment brand, but in actuality do not have diverse employees as indicated by SNS, specifically LinkedIn. We chose LinkedIn because this SNS platform is designed specifically for working individuals, and a recent survey found that it was the top choice among recruiters for online recruitment [26].

Therefore, the purposes of this research are threefold. First, we attempt to expand the literature on recruitment and organizational attraction by investigating the impact of SNS. Secondly, we explore the role of corporate image communicated via a corporate website and how this image is impacted by LinkedIn information that either confirms or disconfirms the company's espoused image. Thirdly, we investigate how inconsistent information from LinkedIn will result in lower ratings of corporate character and thus organizational attraction.

\section{Background}

\subsection{Recruitment}

Organizational recruitment encompasses "all organizational practices and decisions that affect either the number, or types, of individuals that are willing to apply for, or to accept, a given vacancy" [35]. These practices and decisions may be purposeful recruiting, but also can include unintended influences of the reputation or attractiveness of the organization on potential applicants [11]. A general model of the recruitment process characterizes an organization's recruitment activities to include the information conveyed to applicants - the most relevant aspects being completeness, realism, and timeliness [7].

Success in organizational recruitment is indicated by increased job pursuit intentions, job-organization attraction, acceptance intentions, and job choice. Metaanalytic results from recruitment studies have shown that job and organization characteristics, perceptions of the recruitment process, and perceived fit were all important predictors of these recruiting outcomes [11].
Although much of the recruiting research has focused on traditional recruiting methods, Internet recruiting has received growing attention from researchers recently, which is not surprising given its rising popularity as a method for recruitment [10]. Generally, organizational websites have been found to be an effective way to recruit [12] because they can attract a large number of applicants for a relatively low cost. However, there are a number of factors that influence the effectiveness of this recruiting method, such as web site aesthetics, ease of navigation, and information content $[5,13,47]$.

Regarding information content, an organization's website provides organization-controlled information to applicants, but researchers have also begun to investigate the impact of information applicants gain from sources not controlled by the employer. Indeed, information applicants gather from third-party websites have been found to be perceived as more credible than information found on the organization's website [43]. It was further found that, although website characteristics such as technologically advanced features can positively influence applicant perceptions, the applicant's familiarity with the organization (i.e. information from other sources) tempers the relationship [45].

This research highlights the importance of information that applicants receive from sources that are outside the direct control of organizations. As the popularity of SNS grows both for recruiters and applicants [30], investigating the impact of information conveyed and gathered from these sites will provide valuable information to practitioners.

\subsection{Organizational Attraction and Image}

Organizational attraction is operationalized as potential applicants" "interest in an organization as a potential employer and the probability of pursuing employment opportunities and is the most immediate objective of the early stages of recruitment" [1]. Applicants who are not attracted to organizations will not apply to them. Thus, positive perceptions of organizational attraction are necessary to improve the number of potential applicants in a selection pool [46]. Attracting and retaining superior applicants leads to sustained competitive advantages [41].

Barber [4] suggested that organizational attraction be conceptualized across three stages: attracting applicants, maintaining applicant interest, and influencing job choice. Our focus is on the earliest stages, generating and attracting applicants. The early stages of recruitment are generally characterized by potential job applicants leveraging very limited information to refine lists of employment prospects. 
Eventually they choose the most attractive organizations and continue in the job seeking process by actually applying for employment $[1,33]$.

To understand how applicants use the limited information they have in the job seeking process, it is useful to consider how individuals evaluate organizational image, which impacts organizational attraction [11]. The instrumental-symbolic framework [29] stipulates that potential applicants evaluate organizations on an instrumental level, which includes assessments about objective and tangible attributes like salary and benefits. Candidates also assess organizations symbolically with subjective, nontangible imagery, usually ascribing traits to the organization by employing personification. For example, organizations are often described as innovative and trendy [29]. It has been found that symbolic traits explain variance in organizational attraction over and above instrumental assessments [2] and can be construed as an organizations image.

One way potential applicants might initially gain information about an organization is by researching it online. Organizations invest significant resources in promoting a strategic image as a vehicle for recruitment and use their corporate website to portray this image $[10,37,40,41]$, yet the popularity of SNS provides venues for alternative, and perhaps competing, information. In fact, SNS have become one of the most widely used tools for applicants in the job search [39]. However, very few studies have been conducted on organizational websites and recruitment $[1,10,19,20]$, and fewer yet on SNS and recruitment [1]. In fact, in the most recent review of the state of recruitment research, SNS were not mentioned, likely because of the dearth of research on the topic [6]. Preliminary research has shown that applicants deem third-party websites more credible than the organization's own website [43], yet we do not know how potential applicants respond to consistent or inconsistent information online in terms of organizational image and attraction.

\subsection{Warranting}

Warranting theory was originally proposed by Walther and Parks [45] and suggests that 'other provided' information about a target (i.e., another person, or an organization) has a greater impact on receivers than information generated by the target precisely because it is less susceptible to manipulation. Using this approach, humans evaluate warrants-or, information about a target object-and assign a warranting value to that information based on how likely the information may have been manipulated by the target. This warranting principle is critically important today given the variability of information sources about targets. For example, research on SNS found that users whose profiles have comments from 'attractive' friends also were perceived as more attractive [46]. Here, warrants were operationalized as the profile picture associated with the individual leaving a comment on a SNS profile page. This 'other provided' information influenced others' evaluations of the target.

It is important to note that Parks [33] outlined three boundary conditions that must be satisfied for warranting to occur. First, a target, in this case the organization, must make a public claim about their identity (i.e., espoused values or organization). Second, others related to the organization (i.e., employees) must be able to view and comment on the claim. Finally, other potential stakeholders (i.e., the potential job applicants) must be able to view the original claim made by the organization and the comments made by others (i.e., employees) about that claim. We argue that social media facilitates the second and third boundary conditions, as explained below.

\section{Hypothesis Development}

Soelberg [39] proposed that once individuals identify organizations where they would like to work, they try to confirm their choice by gathering additional information. The scope of information available has expanded significantly since 1967, and the cost efficacy of checking SNS is so low that potential candidates surely explore websites such as LinkedIn during their job search process. Additionally, based on image theory [30], job seekers will screen out organizations based on negative information, with negative information receiving more attention and gravity than positive information [20, 28]. Moreover, based in warranting theory, we would expect job applicants to place more value on information gathered via SNS.

The question then becomes what happens when organizations communicate one image, but information available on a SNS is inconsistent with that image? Specifically, if an organization is espousing an image of diversity on its corporate website, but a search of employees of the organization on LinkedIn results in a homogenous, all white workforce, how does this impact perceived attractiveness?

Based in warranting theory, we suggest that there are a variety of warrants about organizations available to potential job seekers. While the warranting value of these information sources may vary, it is likely that individuals use this information when assessing organizational attraction. In this study, we chose to 
employ two information sources: an organization's website and the search results from LinkedIn of that company's employees. Because LinkedIn profile pages are connected to actual people, and these profiles are created and shared for professional and career-related purposes, they are characterized by high levels of integrity and accuracy. As such, they have very high warranting value. On the other hand, company websites are designed to portray a certain image and are easily manipulated by the organization and could possibly portray false information. Thus we argue that the corporate website will have lower warranting value.

Consistent with Park's [33] explication of the three boundary conditions prerequisite for warranting described above, we operationalize the following conditions in our study. First, organizational websites used for recruitment make claims about their identity (i.e., diversity), and LinkedIn profiles allow for others (i.e., employees) to contribute information relative to that claim (analogous to Park's requirement that others be able to comment about the claim). Further, other stakeholders (i.e., potential job applicants) are able to compare the initial claim (the organization's website) with other-provided information about the claim (LinkedIn profiles). Therefore, when organizations claim via their websites that they are diverse, but warrants from the search results containing LinkedIn profiles are inconsistent with this message (i.e., low diversity), job candidates are likely to appraise this inconsistency negatively, extrapolating this inconsistency to trait inferences about the organization.

One approach to investigating the effects symbolic trait images or organizational image involves the use of personification and personality measures [17]. Specifically, using the corporate character scale [17], we examine the symbolic personality characteristics of agreeableness, competence, and enterprise. Organizations that are perceived as agreeable are viewed as trustworthy, likable, and friendly. Enterprising organizations are viewed as modern, adventurous, and bold. Lastly, competent organizations are seen as dependable, efficient, and responsible [17].

Taking into account the preference toward warranting information, inconsistency between the espoused values of diversity on the corporate website and the search results of actual employees on LinkedIn should result in potential applicants viewing the organization as less agreeable, enterprising, and competent. Essentially, the organization will be seen as being deceptive about their actual image, and thus untrustworthy, undependable, and lacking innovation. Thus, we propose the following hypothesis:
Hypothesis 1: Participants in the consistent high diversity condition will have significantly more positive evaluations of organizational a] agreeableness, b] enterprise, and c] competence, opposed to participants in the low diversity condition.

Further, the instrumental-symbolic framework coupled with social identity theory, would predict that individuals use their associations with organizations to provide information about themselves. Thus, most people want to be associated with organizations that they view positively and have positive traits [29, 40]. Agreeableness, enterprise, and competence are all favorable symbolic characterizations of an organization that are related to positive reputations [17]. Based on social identity theory, we expect potential job candidates to desire to be associated with organizations with these positive characteristics.

Organizations that are agreeable are seen as trustworthy and friendly. In their study on corporate character, Davies and colleagues [17] found that agreeableness was the strongest predictor of customer and staff satisfaction and concluded that it is vital to a positive reputation. Further, enterprising organizations are seen as innovative and up-to-date, whereas competent organizations are seen as dependable [17], and these characteristics are also related to a positive reputation. Additionally, Lievens and Highhouse [30] found these dimensions to be directly related to organizational attraction. Thus, we hypothesize:

Hypothesis 2: Evaluations of organizational a] agreeableness, b] enterprise, and c] competence will positively relate to organizational attraction.

Lastly, we posit that it is through the symbolic characteristics that the condition will impact organizational attraction. Based in warranting theory, inconsistent information from a SNS will lead to negative evaluations and consistent information will lead to positive evaluations. Thus, consistent information will lead to higher ratings of agreeableness, enterprise, and competence, and these will be related to higher levels of organizational attraction. Therefore, we hypothesize:

Hypothesis 3: Evaluations of organizational a] agreeableness, b] enterprise, and c] competence will mediate the relationship between the experimental condition and organizational attraction. 


\section{Methods}

\subsection{Experimental Design}

The researchers considered several different designs including the use of actual organizational websites, LinkedIn corporate pages, and the addition of another SNS. However, in order to control as much of the information as possible, the following design was chosen. Each participant began the experiment by answering survey questions addressing job search behavior and SNS use via Qualtrics. Next, participants were exposed to a corporate webpage from a fictitious organization, Remco (Figure 1). This webpage highlights employee diversity at Remco by portraying employees of varied sex, age and ethnicity, as well as by having statements about the importance of diversity. This page was adapted from an actual organization's corporate diversity page.

Figure 1

Remco's corporate diversity website.

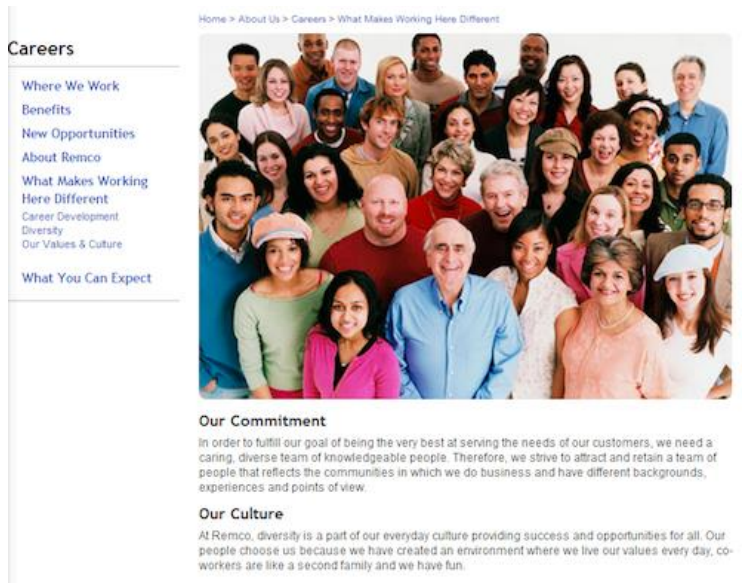

After viewing the corporate diversity webpage, participants were next exposed to the high and low diversity stimulus materials that were created and manipulated by the experimenters. These materials were fictitious LinkedIn pages showing 10 profiles of current Remco employees and were manipulated to be either consistent or inconsistent with Remco's corporate diversity webpage, which depicts high levels of diversity. In the consistent condition, participants were exposed to the high diversity stimulus (Figure 2). In the inconsistent condition, participants were exposed to the low diversity stimulus. The corporate diversity page and LinkedIn profile pages were constructed by manipulating the original website code for both of these webpages.

The stimulus materials were designed to extend Avery's [3] research, which manipulated photos of employees in recruitment advertisements by race across three conditions including balanced, skewed, and uniform. However, unlike Avery's work, the current study manipulated race across more than a black vs. white paradigm by accounting for variation in other races. Further, whereas Avery only looked at recruitment advertising pictures, the intent of this study is to show the actual employees of Remco. To determine the mix of individuals for the diverse and non-diverse conditions, we drew on demographic projections from Judy and D'Amico [28], which projected the American workforce demographics through 2020. We included Hispanic, AfricanAmerican, Caucasian, and Asian-American, as well as a representative number of women in the workforce. The ages of the employees in the LinkedIn profiles were kept to between 25-50 years old.

The two conditions - high diversity and low diversity - systematically varied the images depicting ethnic and gender diversity of current employees on the LinkedIn search results page of our fictitious organization, Remco. The low diversity condition was comprised of all white employees: six white males, occupying low and high levels of the hierarchy, and four white females who occupied only low positions. The high diversity condition was comprised of a diverse ethnic sample of men and women occupying high and low level positions in the organization. Specifically this condition had three Caucasian males and one Caucasian female, one male and female Hispanic, one African-American male and two African-American females, and one Asian-American male.

These conditions used stock photography and care was taken to control for professionalism of dress, attractiveness of individuals, and photo quality. Specifically, a subject matter expert chose pictures that were meant to elicit higher than average ratings of attractiveness in order mitigate other forms of bias, like those against obese persons, or people with unattractive features. Further, the background of all photos was held constant, and the resulting pages were as indistinguishable as possible from genuine LinkedIn pages. After viewing the LinkedIn search results pages (i.e., the condition), participants concluded by answering questions assessing organizational attractiveness.

Figure 2

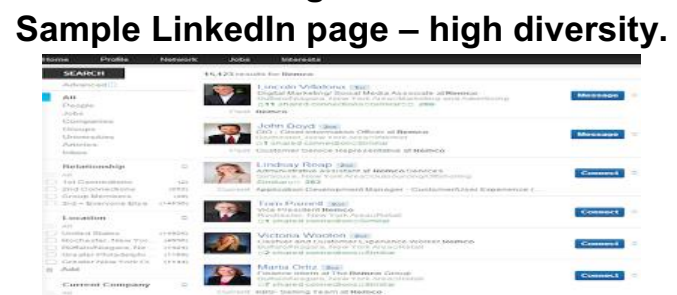




\subsection{Participants}

Participants came from Amazon's Mechanical Turk pool (MTurk) and undergraduate university students. Mturk is an online gathering place for people to seek out or perform digital work. Over 500,000 workers are on Mturk, providing a large and diverse sample (Amazon Web Services, 2011), resulting in respondents with more ethnically diverse backgrounds than typical college samples [8]. Indeed, MTurk has been considered an ideal sample source for experimental and social scientific work [34, 22]. The students were juniors and seniors recruited from the business school of a large Northwestern university and represented $20.7 \%$ of the sample (MTurk respondents represented $73.9 \%$ of the sample). In total, the 123 participates were almost equally male $(55 \%)$ and female $(45 \%)$, with an average age of 29.8 years $(S D=$ 10.1). The sample was $67 \%$ White, $8 \%$ AfricanAmerican, 13\% Asian, 6\% Hispanic. Seventy-eight percent of the sample had jobs with $53 \%$ working fulltime. Of those that worked, the average hours worked per week was $35.8(S D=10.04)$.

\subsection{Measures}

Two measures were used: the Corporate Character Scale [17] and the Organizational Attractiveness Scale [40]. Reliability assessments were: Agreeableness $\alpha=$ .93 , Enterprise $\alpha=.86$, Competence $\alpha=.87$, and Organizational Attractiveness $\alpha=.89$.

\section{Results}

\subsection{Manipulation Check}

Prior to the main data collection, two manipulation checks were conducted. Separate manipulation checks were conducted because the main data collection effort consisted of participants from two separate sourcesundergraduate university students and participants solicited via Amazon's MTurk. Participants were asked to evaluate the perceived levels of diversity in the stimulus materials described above.

Both manipulation checks proved successful. Results of a one-way ANOVA for the university student sample revealed that perceptions of diversity across the conditions differed significantly, $F(2,46)=$ $14.28, p<.01$. The low diversity condition $(\mathrm{M}=3.33$, $S D=1.21)$ was perceived as significantly less diverse than the high diversity condition $(\mathrm{M}=2.00, S D=.88)$. Consistent results were seen in the Mturk sample. Perceptions of diversity across the conditions differed significantly $F(2,66)=4.84, p=.01$, with the low diversity condition $(M=3.24, S D=1.29)$ being perceived as significantly less diverse than the high diversity condition $(M=2.26, S D=1.01)$.

\subsection{Descriptive Statistics}

Descriptive statistics of study variables are reported in Table 1. As expected, agreeableness, enterprise, and competence were significantly and positively related to each other. Organizational attraction was significantly and positively related to agreeableness $(r=0.74, p<$

$.01)$, enterprise $(r=0.58, p<.01)$, and competence $(r=$ $0.47, p<.01)$. Interestingly, the condition was only related to agreeableness $(r=0.18, p<.05)$. Race, gender, and age were not significantly related to any of the study variables but were retained as control variables because of their theoretical significance in this study.

\subsection{Measurement Model}

Because our data is cross sectional in nature, we tested for possible bias due to common method variance (CMV) in our sample. Items representing the corporate character variables and organizational attractiveness were entered into an Exploratory Factor Analysis (EFA) to determine the level of variance attributable to the relationships of interest and not the measurement method. The KMO measure for sampling adequacy was 0.92 , supporting the use of factor analysis. Using Promax rotation, Scree test analysis revealed four distinct factors accounting for $63.62 \%$ of the total variance with factor loading patterns consistent with the proposed constructs. This was further tested using Confirmatory Factor Analysis (CFA). Items representing the four self-rated latent variables were tested. The four-factor model $\left(\chi^{2}=\right.$ 1141.73, $d f=428$; CFI $=0.83$; RMSEA $=0.09$ ) fit the data significantly better than the alternative nested models $(p<.01)$, providing further support for factor discrimination demonstrating that bias due to $\mathrm{CMV}$ is not an issue in the present sample.

\subsection{Hypotheses Testing}

Because the use of SNS in recruitment is relatively under researched, we first sought to understand which of the popular SNS potential job seekers use in their job hunt process. Although the organization's website was a popular choice among our participants $(60 \%)$, $65 \%$ of respondents reported using Facebook as a source of prospective employer information, with LinkedIn closely following (59\%). Only 31\% of respondents reported using Twitter as an information 
source, whereas $46 \%$ and $49 \%$ reported using resume websites (e.g., CareerBuilder.com, Monster.com, etc) and the news, respectively (please note that respondents were allowed to check more than one source).

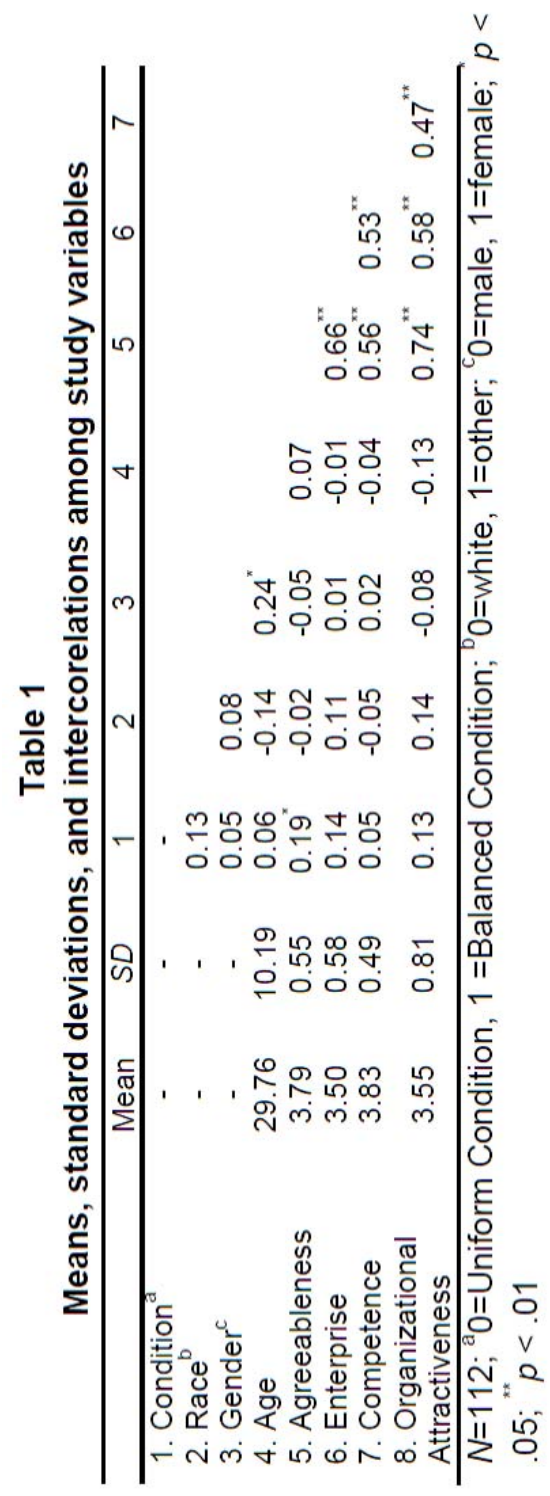

In order to test direct and indirect effects while utilizing bootstrapping methods, Hayes' [24] PROCESS mediation model was used to test the hypotheses (Table 2). Hypothesis 1 argues that individuals in the high diversity condition, giving information consistent with the corporate website, will have more favorable evaluations of agreeableness, enterprise, and competence than those in the low diversity condition. This was tested in mediator models 1-3. Controlling for gender, race, and age, the condition had a significant and positive effect on respondents' ratings of agreeableness $(\beta=0.21, p<$
$.05)$ such that higher scores were expressed in the high diversity condition $(M=3.88 S D=0.43)$ than the low diversity condition $(M=3.67, S D=0.63)$. However, the condition did not have a significant effect on enterprise $(\beta=0.15, n s)$ or competence $(\beta=0.06, n s)$. Thus, Hypothesis 1a was supported but Hypotheses $1 \mathrm{~b}$ and 1c were not.

Table 2

Direct and Indirect Effects

\begin{tabular}{|c|c|c|c|c|}
\hline Predictor & $\bar{\beta}$ & $S E$ & & \\
\hline & Mediato & Todel & Agree & leness) \\
\hline Constant & 3.69 & 0.21 & & $36^{* *}$ \\
\hline Condition $^{a}$ & 0.21 & 0.10 & & \\
\hline Gender ${ }^{b}$ & -0.08 & 0.11 & & \\
\hline Race $^{c}$ & -0.03 & 0.11 & & \\
\hline Age & 0.00 & 0.00 & & \\
\hline & Media & Mode & 2 (Ent & orise) \\
\hline Constant & 3.39 & 0.18 & & $77^{\star *}$ \\
\hline Condition $^{a}$ & 0.15 & 0.11 & & \\
\hline Gender ${ }^{b}$ & 0.00 & 0.11 & & \\
\hline Race $^{c}$ & 0.11 & 0.12 & & \\
\hline Age & -0.00 & 0.00 & & \\
\hline & Mediat & Model & (Com & tence) \\
\hline Constant & 3.89 & 0.16 & & $7^{* *}$ \\
\hline Condition $^{a}$ & 0.06 & 0.09 & & \\
\hline Gender $^{\mathrm{b}}$ & 0.03 & 0.10 & & \\
\hline Race $^{c}$ & -0.07 & 0.10 & & \\
\hline Age & -0.00 & 0.00 & & \\
\hline & Depeno & $\begin{array}{l}\text { t Mod } \\
\text { ttract }\end{array}$ & $\begin{array}{l}\text { (Orga } \\
\text { eness) }\end{array}$ & ational \\
\hline $\begin{array}{l}\text { Constant } \\
\text { Agreeableness }\end{array}$ & $\begin{array}{r}-0.57 \\
0.97\end{array}$ & $\begin{array}{l}0.45 \\
0.13\end{array}$ & & \\
\hline Enterprise & 0.15 & 0.12 & & \\
\hline Competence & 0.05 & 0.13 & & \\
\hline Gender ${ }^{b}$ & -0.04 & 0.10 & & \\
\hline Race $^{\mathrm{c}}$ & 0.22 & 0.11 & & \\
\hline Age & -0.01 & 0.00 & & \\
\hline & $\begin{array}{l}\text { Direc } \\
\text { Orgar }\end{array}$ & $\begin{array}{l}\text { ffect c } \\
\text { ational }\end{array}$ & $\begin{array}{l}\text { Condi } \\
\text { Attract }\end{array}$ & $\begin{array}{l}\text { non } \\
\text { ness }\end{array}$ \\
\hline & -0.03 & 0.10 & & \\
\hline & $\begin{array}{c}\text { Indire } \\
\text { Orgar }\end{array}$ & $\begin{array}{l}\text { Effect } \\
\text { ational }\end{array}$ & $\begin{array}{l}\text { Cond } \\
\text { Attract }\end{array}$ & $\begin{array}{l}\text { on on } \\
\text { ness }\end{array}$ \\
\hline & Boot & Boot & Boot & Boot \\
\hline & $\begin{array}{c}\text { indirect } \\
\text { effect }\end{array}$ & $S E$ & $\begin{array}{c}\text { lower } \\
\mathrm{Cl}^{\mathrm{d}}\end{array}$ & $\begin{array}{c}\text { upper } \\
\mathrm{Cl}^{\mathrm{d}}\end{array}$ \\
\hline Agreeableness & 0.20 & 0.10 & 0.02 & 0.44 \\
\hline Enterprise & 0.02 & 0.03 & -0.01 & 0.13 \\
\hline Competence & 0.00 & 0.01 & -0.01 & 0.06 \\
\hline
\end{tabular}

$N=109 ;$ Unstandardized regression coefficients reported; Bootstrap sample size = 1000; a $0=$ Uniform Condition, 1 =Balanced Condition; ${ }^{\mathrm{b}} 0=$ male, $1=$ female; ${ }^{\mathrm{c}} 0=$ white, $1=$ other; ${ }^{\mathrm{d}} \mathrm{Cl}=$ confidence interval; ${ }^{*} p<.05 ;{ }^{* *} p<.01$

Hypotheses 2a-c stated that agreeableness, enterprise, and competence positively relate to 
organizational attractiveness. Supporting Hypothesis 2a, while controlling for gender, race, age, and the other corporate character factors, agreeableness was significantly and positivity related to organizational attractiveness $(\beta=0.97, p<.01)$. However, enterprise $(\beta=0.15, n s)$ and competence $(\beta=0.05, n s)$ were not and thus Hypotheses $2 \mathrm{~b}$ and $2 \mathrm{c}$ were not supported.

Hypotheses 3a-c stated that the relationship between the condition and organizational attractiveness is mediated by agreeableness, enterprise, and competency, respectively. Bootstrapped results for indirect effects of the condition on organizational attractiveness indicated that this relationship is mediated by agreeableness $(\beta=0.20,95 \% \mathrm{CI}$; LLCI $=$ 0.02 , ULCL $=0.44)$, but not enterprise $(\beta=0.02,95 \%$ $\mathrm{CI}$; $\mathrm{LLCI}=-0.01$, ULCL $=0.13)$ or competence $(\beta=-$ $0.07,95 \% \mathrm{CI}$; LLCI $=-0.01$, ULCL $=0.06$ ). Thus, Hypothesis $3 \mathrm{a}$ was supported but not $3 \mathrm{~b}$ and $3 \mathrm{c}$.

\section{Discussion}

The results of this study provide evidence that inconsistency between diversity claims on the organization's website and diversity observed on the LinkedIn profile search result on the organization's employees contributed to lower perceptions of the organization's agreeableness, which led to lower perceived attractiveness. This is consistent with the idea of warranting theory in that potential applicants placed more value on the disconfirming information contained on the SNS rather than the information on the corporate website. On the other hand, consistent information led potential applicants to rate the organization as more agreeable and thus more attractive. Agreeable organizations are seen as trustworthy, sincere, straightforward, supportive, and socially responsible. When an organization's diversity brand espoused on their website is consistent with their employees and LinkedIn results show diverse employees, these organizations are seen as being social responsible and sincere. This positive employer image or brand is then related to higher levels of attraction, which reconfirms Turban and Greening's [42] conclusion that social responsible organizations have an advantage in recruitment and selection. However, organizations need to be careful espousing values that do not reflect reality. The rise of social media allows potential job applicants a great deal of information about the organization, which is not directly controllable by the organization. Further, based on warranting theory, this third party information is seen as more valuable and credible, and when inconsistent with the organization's desired brand, is damaging in the recruitment process.

\subsection{Practical Implications}

Organizations should recognize the detrimental effects of inconsistency between espoused and enacted values. Argyris [2] characterized such inconsistency as indicative of inherent organizational flaws. The results of this research provide evidence that applicants may share this belief, at least when it comes to the espoused value of diversity. Inconsistency may signal a red flag to applicants. Organizations can act to remedy the inconsistency by working toward actual enactment of their espoused commitment to diversity. Additionally, it would behoove organizations to take a strategic approach to managing their online persona, making sure their own websites reflect the same information that can be found on SNS. This may mean acknowledging that diversity is a priority on their website and recognizing that it is a work in progress, which would lead the warranted information available on SNS to be consistent with the espoused information on the corporate website.

Further, this research notes the importance applicants place on diversity. In order to attract the best and brightest candidates, organizations have to work more deliberately and strategically to achieve diverse workforces. The demographic makeup of the employees of top organizations in their respective fields ( $70 \%$ male, $61 \%$ white, and $2 \%$ black at Google) indicates that there are still pools of prospective candidates that remain untapped. Seeking employees from underrepresented groups provides competitive advantage for organizations in part because of the increased attractiveness to future applicants.

\subsection{Strengths, Limitations, and Future Research}

The strengths of this study is the experimental design. Experiments allow researchers to focus only on relevant variables, and limit effects of environmental factors. This study isolated one organization in order to test the effects of social media.

Another strength is the use of MTurk to recruit participants. MTurk provides large, more diverse samples than a sample of college provides [8]. The robustness of the sample enhances the study's generalizability to the broader workforce [16] by minimizing the sampling error that might occur from sampling only one organization or group.

This study also should be viewed in light of its limitations. Although the experimental design is valuable for isolating the relevant variables, the attractiveness of the fictional employees was held 
constant at a higher level than average. However, due to constraints, attractiveness was not assessed via survey measurement but rather subject matter experts were used to judge attractiveness. Future research should explore the role of the attractiveness of current employee as well as actual job candidates for a real organization.

In addition, we were only able to test applicant perceptions as they related to one dimension of organizational values - diversity. Future research should explore how SNS interact with organization websites regarding other kinds of espoused values like social responsibility, organizational creativity, work/life balance, and opportunities for growth. Additionally, this study did not attempt to analyze the affects of diversity on actual performance in the organization, as it is well -known that poorly managed diversity leads to less than optimal outcomes for organizations. Moreover, this study only examined one SNS, LinkedIn, and although this site is well used by recruiters and job seekers, other sites might prove interesting in follow-up studies.

\section{References}

[1] D. G. Allen, R. V. Mahto, and R. F. Otondo, "Web-based recruitment: effects of information, organizational brand, and attitudes toward a Web site on applicant attraction", Journal of Applied Psychology, 92(6), 2007, pp. 1696 .

[2] Argyris, C., Reasoning, learning, and action: Individual and organizational, Jossey-Bass, .San Francisco, 1982.

[3] D.R. Avery, "Reactions to diversity in recruitment advertising - are differences black and white?", Journal of Applied Psychology, 88, 2003, pp. 672-679.

[4] Barber, A. E. Recruiting employees: Individual and organizational perspectives. Sage Publications, Inc. 1998.

[5] P. W. Braddy, A. W. Meade, and C. M. Kroustalis, "Organizational recruitment website effects on viewers' perceptions of organizational culture", Journal of Business and Psychology, 20(4), 2006, pp. 525-543.

[6] J. A. Breaugh, "Employee recruitment: Current knowledge and important areas for future research", Human Resource Management Review, 18(3), 2008, pp. 103-118.

[7] J. A. Breaugh, "Employee recruitment" Annual Review of Psychology, 64, 2013, pp. 389-416.

[8] M. Buhrmester, T. Kwang, and S.D. Gosling, “Amazon's Mechanical Turk: A new source of inexpensive, yet highquality, data?", Perspectives on Psychological Science, 6, 2011, pp. 3-5.
[9] R. Caers, and V. Castelyns, "LinkedIn and Facebook in Belgium: The Influences and Biases of Social Network Sites in Recruitment and Selection Procedures", Social Science Computer Review, 29(4), 2011, pp. 437-448.

[10] P. Cappelli, "On-line recruiting”, Harvard business review, 79(3), 2001, pp.139-146.

[11] D. S. Chapman, K. L. Uggerslev, S. A. Carroll, K. A. Piasentin, and D. A. Jones, "Applicant attraction to organizations and job choice: a meta-analytic review of the correlates of recruiting outcomes.", Journal of Applied Psychology, 90(5), 2005, pp. 928-944.

[12] D. S. Chapman, and J. Webster, "The use of technologies in the recruiting, screening, and selection processes for job candidates", International Journal of Selection and Assessment, 11(2-3), 2003, pp. 113-120.

[13] R. T. Cober, D. J. Brown, and P. E. Levy, "Form, content, and function: an evaluative methodology for corporate employment web sites", Human Resource Management, 43(2-3), 2004, pp. 201-218.

[14] R. T. Cober, D. J. Brown, P. E. Levy, A. B. Cober, and L. M. "Keeping, Organizational web sites: Web site content and style as determinants of organizational attraction", International Journal of Selection and Assessment, 11(2-3), 2003, pp. 158-169.

[15] S. Cromheecke, G. Hoye, and F. Lievens, "Changing things up in recruitment: Effects of a 'strange' recruitment medium on applicant pool quantity and quality", Journal of Occupational and Organizational Psychology, 86(3), 2013, pp. 410-416.

[16] L. J. Cronbach, N. Rajaratnam, and G. C. Gleser, "Theory of generalizability: A liberalization of reliability theory", British Journal of Statistical Psychology, 16(2), 1963, pp. 137- 163.

[17] G. Davies, R. Chun, R. V. da Silva, and S. Roper, “A corporate character scale to assess employee and customer views of organization reputation" Corporate Reputation Review, 7, 2004, pp.125-146.

[18] H. K. Davison, C. Maraist, and M. N. Bing, "Friend or foe? The promise and pitfalls of using social networking sites for HR decisions", Journal of Business and Psychology, 26(2), 2011, pp. 153-159.

[19] H. K. Davison, C. C. Maraist, R. H. Hamilton, and M. N. Bing, "To screen or not to screen? Using the internet for selection decisions", Employee Responsibilities and Rights Journal, 24(1), 2012, pp.1-21.

[20] B. R. Dineen, and R. A. Noe, "Effects of customization on application decisions and applicant pool characteristics in a web-based recruitment context", Journal of Applied psychology, 94(1), 2009, pp. 224. 
[21] B. R. Dineen, S. R. Ash, and R. A. Noe, “A Web of applicant attraction: person-organization fit in the context of Web-based recruitment", Journal of Applied Psychology, 87(4), 2002, pp. 723

[22] K. H. Ehrhart, and J. C. Ziegert, "Why are individuals attracted to organizations?", Journal of Management, 31(6), 2005, pp. 901-919.

[23] J. K. Goodman, C.E. Cryder, and A. Cheema, "Data collection in a flat world: the strengths and weaknesses of Mechanical Turk samples", Journal of Behavioral Decision Making, 26, 2013, pp. 213-224.

[24] Hayes, A. F. Introduction to mediation, moderation, and conditional process analysis: A regression-based approach, Guilford Press, 2013.

[25] D.A. Harrison, K.H. Price, and M.P. Bell, "Beyond relational demography: Time and effects of surface- and deep-level diversity on work group cohesion" The Academy of Management Journal, 41 (1), 1998, pp. 96-107.

[26] S. Highhouse, M. J. Zickar, T. J. Thorsteinson, S. L. Stierwalt, and J. E. Slaughter, "Assessing company employment image: An example in the fast food industry", Personnel Psychology, 52(1), 1999, pp. 151-172.

[27] Jobvite, "Social recruiting results", 2010. www.jobvite.com

[28] Judy, R.W. and C. D'Amico, Workforce 2020: Work and Workers in the $21^{\text {st }}$ Century. Hudson Institute, 1997, Indianapolis, IA.

[29] D. Kahneman, and A. Tversky, "Prospect theory: An analysis of decision under risk", Econometrica: Journal of the Econometric Society, 1979, pp. 263-291.

[30] F. Lievens, and S. Highhouse, "The relation of instrumental and symbolic attributes to a company's attractiveness as an employer", Personnel Psychology, 56(1), 2003, pp. 75-102.

[31] S. A. Madia, "Best practices for using social media as a recruitment strategy", Strategic HR Review, 10(6), 2011, pp. $19-24$.

[32] L. D. Ordóñez, L. Benson III, and L. R. Beach, “Testing the compatibility test: How instructions, accountability, and anticipated regret affect prechoice screening of options", Organizational Behavior and Human Decision Processes, 78(1), 1999, pp. 63-80.

[33] M. Parks, "Boundary conditions for the application of three theories of computer-mediated communication to Myspace", Journal of Communication, 61(4), 2011, pp. 557574.
[34] D. J. Power, and R. J. Aldag, "Soelberg's job search and choice model: A clarification, review, and critique", Academy of Management Review, 10(1), 1985, pp. 48-58.

[35] D.G. Rand, "The promise of Mechanical Turk: How online labor markets can help theorists run behavioral experiments", Journal of Theoretical Biology, 299, 2012, pp. 172-179.

[36] S. L. Rynes, "Recruitment, job choice, and post-hire consequences: A call for new research directions", Handbook of industrial and organizational psychology, Consulting Psychologists Press, Palo Alto, CA, 1991.

[37] S. L. Rynes, and A. E. Barber, "Applicant attraction strategies: An organizational perspective", Academy of Management Review, 15(2), 1990, pp. 286-310.

[38] S. L. Rynes, R. D. Bretz, and B. Gerhart, "The importance of recruitment in job choice: A different way of looking”, Personnel Psychology, 44(3), 1991, pp. 487-521.

[39] P.O. Soelberg, " 'Unprogramed decision making”, Industrial Management Review, 8, 1967, pp.19-29.

[40] Stopfer, J. M. and S. D. Gosling, "Online social networks in the work context", The psychology of digital media at work Psychology Press. London, UK. 2013.

[41] D. B. Turban, and D. W. Greening, "Corporate social performance and organizational attractiveness to prospective employees.", Academy of Management Journal, 40(3), 1997, pp. $658-672$.

[42] D. B. Turban, M. L. Forret, and C. L. Hendrickson, "Applicant attraction to firms: Influences of organization reputation, job and organizational attributes, and recruiter behaviors", Journal of Vocational Behavior, 52(1), 1998, pp. 24-44.

[43] H. C. Triandis, M. Dunnette, and L. Hough (Eds.) Handbook of industrial and organizational psychology (Vol. 4, pp. 769-827). Palo Alto, CA: Consulting Psychologists Press, 1994.

[44] H. J. Walker, H. S. Feild, W. F. Giles, J. B. Bernerth, and J. C. Short, "So what do you think of the organization? A contextual priming explanation for recruitment Web site characteristics as antecedents of job seekers' organizational image perceptions", Organizational Behavior and Human Decision Processes, 114(2), 2011, pp. 165-178.

[45] Walther, J. and M. Parks , "Cues filtered out, cues filtered in: Computer-mediated communication and relationships", Handbook of interpersonal communication. 3rd edition, 2002.

[46] I. O. Williamson, D. P. Lepak, and J. King, "The effect of company recruitment web site orientation on individuals' perceptions of organizational attractiveness" Journal of Vocational Behavior, 63(2), 2003, pp.242-26 